\title{
DO AMOR E DO DESEJO: SOBRE DOIS POEMAS DE LIA VIEIRA
}

Henrique Marques Samyn

Resumo: O artigo propõe interpretações para dois poemas de Lia Vieira, uma das mais importantes escritoras negras brasileiras, com largo histórico de contribuição para os Cadernos Negros - publicação coletiva de autores negros brasileiros regularmente editada há mais de quarenta anos - e obras selecionadas para antologias publicadas no Brasil e no exterior. As análises propostas, acerca dos poemas "Meu Zumbi" (originalmente publicado em Cadernos Negros 15, de 1992) e "Ânsia" (originalmente publicado em Cadernos Negros 19, de 1996), tencionam enfatizar o tratamento de dois temas centrais da produção literária de Lia Vieira - o amor e o desejo como expressões de um corpo racializado-, concedendo relevo apara aspectos formais e retóricos das composições.

Palavras-chave: Amor. Desejo. Literatura de autoria feminina. Literatura negro-brasileira.

Abstract: The aim of this paper is to present interpretations of two poems by Lia Vieira, one of the most important Brazilian black writers, with a long history of contributing to Cadernos Negros - a collective publication by black Brazilian authors, regularly edited for over forty years - and works selected for anthologies published in Brazil and abroad. The interpretations of "Meu Zumbi" (originally published in Cadernos Negros 15, 1992) and "Ânsia" (originally published in Cadernos Negros 19, 1996) aim to highlight the treatments of two central themes of Vieira's literary work - love and desire as expressions of a racialized body -, with an emphasis on formal and rhetorical aspects of the compositions.

Keywords: Love. Desire. Literature by women. Brazilian black literature.

\section{PREÂMBULO}

Meu propósito neste artigo é apresentar algumas considerações acerca de dois poemas assinados por Lia Vieira: 
"Ânsia", originalmente publicado no décimo nono volume dos Cadernos Negros (1996), cuja versão extraio da compilação Amor e outras revoluções, organizada por Éle Semog (2019); e "Meu Zumbi", originalmente publicado no décimo quinto volume dos Cadernos Negros (1992). O que tenciono, ao comentar essas duas composições da referida autora - um dos nomes mais importantes da literatura negro-brasileira, como atestam seu largo histórico de contribuição nos Cadernos Negros ${ }^{1}$, considerando-se inclusive sua presença em coletâneas organizadas pelo coletivo Quilombhoje ${ }^{2}$; ou a republicação de suas obras em relevantes antologias, publicadas no Brasil $^{3}$ e no exterior ${ }^{4}$ - é tecer algumas considerações sobre um par de temas centrais de sua produção lírica: o amor e o erotismo. Como evidenciarei ao longo das próximas páginas, esses motivos emergem na poética de Lia Vieira arregimentando questionamentos políticos e ontológicos profundamente enraizados no ideário negro-brasileiro.

1 Contos e poemas publicados em Cadernos Negros 14 (1991); Cadernos Negros 15 (1992); Cadernos Negros 16 (1993); Cadernos Negros 18 (1995); Cadernos Negros 19 (1996); Cadernos Negros 20 (1997); Cadernos Negros 22 (1999); Cadernos Negros 24 (2001); Cadernos Negros 26 (2003); Cadernos Negros 28 (2005); e Cadernos Negros 42 (2019).

2 Como os volumes Cadernos Negros: os melhores poemas e Cadernos negros: os melhores contos, ambos de 1998, organizados por Esmeralda Ribeiro e Márcio Barbosa; ou Cadernos Negros: três décadas, volume igualmente organizado por Esmeralda Ribeiro e Márcio Barbosa, publicado em 2008.

3 À guisa de exemplo, cito apenas a antologia crítica Literatura e afrodescendência no Brasil, organizada por Eduardo de Assis Duarte e publicada em quatro volumes (2014).

4 À guisa de exemplo, cito apenas a antologia Moving beyond boundaries, editada por Carole Boyce Davies e Molara Ogundipe-Leslie (1995). 


\section{SOBRE O AMOR: "ÂNSIA"}

Começo propondo alguns apontamentos sobre "Ânsia", poema originalmente publicado em Cadernos Negros 19 (1996) - em data posterior, portanto, à da publicação original de "Meu Zumbi", segunda composição que analisarei neste artigo; contudo, essa é uma ordenação mais conveniente para os fins da minha argumentação. Transcrevo a obra:

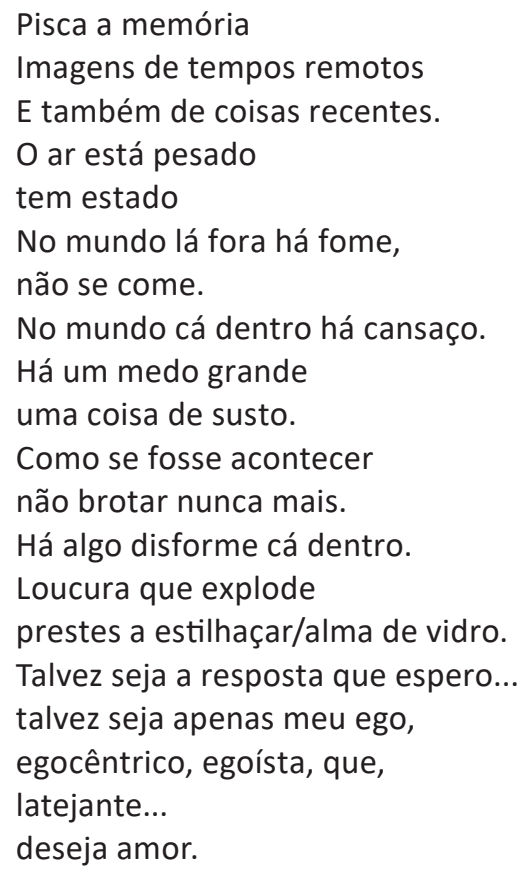

Nos primeiros versos, importa observar o modo como a evocação da memória institui uma indefinição temporal, ao fazer convergir um conjunto imagético que associa recordações 
pretéritas - os "tempos remotos" (v. 2) - e momentos mais próximos do agora - as "coisas recentes" (v. 3). O efeito imediato dessa convergência é o deslocamento da subjetividade lírica para um espaço intervalar, desde um esvanecimento do presente; não obstante, disso deriva um distanciamento em relação à atualidade, fator condicionante para a disposição reflexiva preponderante nos versos seguintes.

Todavia, antes de avançar nos comentários, parece-me relevante enfatizar dois pontos. Primeiro, note-se como isso evidencia o recurso a um expediente retórico, com propósitos estéticos definidos: trata-se de estabelecer um posicionamento definido para o eu lírico, de modo a mobilizar os elementos necessários para a construção da discursividade poética. Em segundo lugar, em termos formais, ressalte-se a estruturação métrica dos versos: o poema se abre com um verso tetrassílabo, de estrutura coriâmbica (o que já institui, em termos rítmicos, um espaço intervalar, pela presença das duas sílabas átonas entre as tônicas); a este, segue-se um par de octossílabos, cuja estrutura não é a mesma - no primeiro, há um iambo seguido por dois anapestos; no segundo, o iambo é deslocado para o centro do verso (o que, no que diz respeito ao ritmo, favorece a sugestão de uma consciência divagante). Perceba-se, em outras palavras, como o domínio 
dos recursos próprios da criação poética se faz evidente na construção formal dos versos.

O que encontramos no seguinte trecho do poema, entretanto, não é um pleno afastamento da percepção do tempo presente; o que ocorre, com efeito, é uma suspensão das urgências menores do cotidiano, propiciando uma percepção crítica do mundo. Se, ao afirmar que "[o] ar está pesado" (v. 4), a subjetividade lírica poderia resvalar em digressões solipsistas - acerca, por exemplo, de seu estado anímico ou emocional, em decorrência de quaisquer contingências pessoais -, esse risco não se concretiza, uma vez que a consciência ensaia um movimento excêntrico: menos lhe importa refletir sobre si mesma (isto é: o eu) do que ponderar sobre a realidade exterior (isto é: o mundo). O quinto verso da composição materializa esse deslocamento: se, a princípio, o verso "tem estado" pode parecer acidental ou desimportante, é crucial notar como ele efetiva a compreensão de que o arranjo de circunstâncias ultrapassa a instância individual, remetendo a uma soma de acontecimentos inscritos em um âmbito mais amplo.

Novamente, cabe atentar para o fato de que há uma estruturação formal subjacente: o quarto verso, hexassilábico ("O ar está pesado"), tem uma composição 
iâmbica, o que instaura provisoriamente uma constância em termos rítmicos; todavia, trata-se de uma estabilização efêmera, o que já é insinuado pelo quinto verso, que se reduz a um anapesto ("tem estado"). Se o equilíbrio rítmico do conjunto é sustentado pela complementaridade entre as soluções métricas, sobretudo no que tange à transição dos octossílabos para o hexassílabo, o arranjo de iambos e anapestos produz um andamento que preserva o jogo de deslocamentos antes aludido.

No segmento que se estende do sexto ao décimo versos, deparamo-nos com uma contraposição entre dois âmbitos: de um lado, o polo objetivo; de outro lado, o polo subjetivo. 0 primeiro polo (v. 6-7) figura o espaço exterior, representado pelo mundo, conforme evocado pela consciência: "No mundo lá fora há fome, / não se come". Destaco, em primeiro lugar, a importância retórica perceptível em duas construções pleonásticas: a que reforça a exterioridade do mundo, identificando-o ao espaço externo (ressaltando, portanto, a relação "mundo" = "fora"); e a que enfatiza a precária condição das pessoas que nele habitam (se "há fome", é porque "não se come"). Essas afirmações tautológicas operam para introduzir, tacitamente, uma ruptura em relação ao que vinha sendo afirmado: o registro difuso que 
predomina no trecho inicial do poema (refiro-me, por óbvio, ao que se estende do primeiro ao quinto versos) cede lugar a asserções cuja peremptoriedade assume um tom de denúncia.

Perceba-se, portanto, que a associação entre as construções pleonásticas converge para um clamor cujo conteúdo não emerge de modo arbitrário; se a fome é um motivo há muito presente na literatura brasileira pensemos em A Fome, de Rodolfo Teófilo (1890); em $O$ Quinze, de Rachel de Queiroz (1930); ou em Vidas Secas, de Graciliano Ramos (1938), entre muitos outros exemplos possíveis -, no que diz respeito ao âmbito contemporâneo, trata-se de um tema fulcral na produção negro-brasileira. Isso pode ser percebido pela evocação de dois de seus mais importantes nomes: Carolina Maria de Jesus e Solano Trindade. Em Carolina, a fome ocupa um lugar central não apenas em Quarto de despejo (1960) - em que a fome é qualificada como uma atualização da escravatura (JESUS, 1960, p. 27) ou como "a pior coisa do mundo" (JESUS, 1960, p. 167) -, mas também em obras como Pedaços da fome (1963), em que assombra a protagonista - "Maria Clara tinha receio de passar fome. Ficava horrorizada quando via as mulheres pobres vagando pelas ruas pedindo esmolas" 
(JESUS, 1963a, p. 154) - e em Provérbios (1963b), no qual a fome é qualificada como "a dinamite do corpo humano" (1963b, p. 29). Da obra de Solano Trindade, parece-me suficiente citar duas estrofes de "Tem gente com fome", publicado em Cantares ao meu povo (1961):

\author{
Trem sujo da Leopoldina \\ correndo correndo \\ parece dizer \\ tem gente com fome \\ tem gente com fome \\ tem gente com fome \\ Piiiiii \\ $[\ldots]$ \\ Só nas estações \\ quando vai parando \\ lentamente começa a dizer \\ se tem gente com fome \\ dá de comer \\ se tem gente com fome \\ dá de comer \\ se tem gente com fome \\ dá de comer \\ [...]. \\ (TRINDADE, 1961, p. 65-66)
}

Não é preciso enfatizar que a centralidade da fome como motivo no corpus literário de autoria negra se justifica pela opressão historicamente imposta sobre esse contingente racializado da população, sobre o qual pesam as heranças do período escravista; se, nas palavras de Sueli Carneiro, 
"pobreza tem cor no Brasil" (2011, p. 57), uma das inevitáveis consequências disso é a insegurança alimentar.

Perceba-se, portanto, como os versos de Lia Vieira evidenciam um conjunto de elementos que se articulam desde uma força empática: enquanto mulher negra politicamente alerta, ao abrir-se para o mundo, a autora empírica não pode negligenciar o sofrimento de seus pares - ainda que não esteja sujeita à mesma dor, como denota a relação de exterioridade figurada no verso. O eu lírico vocaliza, por conseguinte, uma demanda coletiva, em que transparece uma experiência do mundo determinada por uma condição específica (racializada).

Os versos seguintes descrevem um movimento em sentido contrário: após abrir-se para fora, a subjetividade volta-se para dentro, recuperando o pendor reflexivo presente nos versos iniciais da composição. Esse é, com efeito, o registro predominante do poema, que permanecerá até o seu desfecho - embora, como já anteriormente mencionei e logo voltarei a ressaltar, disso não resulte um isolamento solipsista: o eu pressupõe o outro, não como alteridade, mas como elemento constitutivo. É por isso que a dor alheia é absorvida pela subjetividade, como efeito de uma experiência profundamente compartilhada. Há, portanto, uma relação analógica entre as 
dimensões objetiva e subjetiva que, na superfície textual, se materializa por uma construção anafórica:

No mundo lá fora há fome, (v. 6)

[...]

No mundo cá dentro há cansaço. (v. 8)

Os efeitos decorrentes (o cansaço, o medo, o susto) ensejam estados que remetem à desesperança - a possibilidade de "não brotar nunca mais" (v. 12) - e desencadeiam uma desestabilização que coloca em risco a própria configuração subjetiva: é a "Loucura que explode / prestes a estilhaçar / alma de vidro" (v. 14-15). Pareceme interessante ressaltar que esta passagem sugere um duplo espedaçamento: primeiro, em consequência de um possível colapso da razão, ameaçada pela sobrecarga afetiva; segundo, como resultado de um estilhaçamento da própria alma - ou seja: de uma aniquilação ontológica -, cuja fragilização é figurada pela referência a uma constituição vítrea.

Este é o segmento do poema em que a vulnerabilização do eu lírico atinge um ponto limítrofe. Há por trás disso, é certo, uma disposição da própria subjetividade; não obstante, subjaz a esse risco um comprometimento inalienável em termos éticos e existenciais - com seus semelhantes: sabendo-se negra, reconhecendo-se irmã de todas e todos 
que compartilham essa condição racializada, a subjetividade poética deliberadamente se converte num abrigo para suas dores e aflições, em que pesem as consequências disso para sua própria integridade. Esse movimento, entretanto, é tão temerário quanto necessário, na medida em que constitui o compulsório desdobramento de uma consciência política e refratária a quaisquer concessões.

Chegamos, finalmente, aos versos que encerram a composição. Neste momento, é sobretudo importante atentar para os jogos de repetições, que produzem notáveis efeitos estéticos e retóricos:

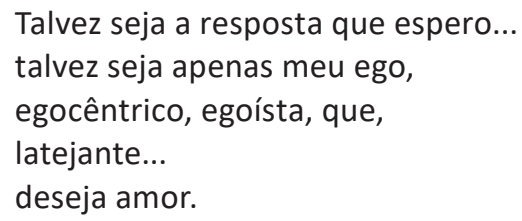

Novamente, Lia Vieira recorre ao paralelismo anafórico desta feita, para promover uma sutil mudança no registro discursivo, convertendo a situação limítrofe em um derradeiro momento de reflexão: já imposta pelo advérbio, a modulação reconhece, inicialmente, o voluntarismo subjacente à crise subjetiva (v. 16-17); num segundo momento, as ressonâncias de fundo pleonástico (v. 17-18) operam, na verdade, como um recurso para viabilizar um questionamento radical sobre a própria subjetividade e suas demandas: tudo se 
resumiria, afinal, às arbitrárias exigências de um ego incapaz de abandonar a posição cêntrica, ou de agir viciosamente em prol de si mesmo? A resposta a esse questionamento assoma, entretanto, no par de versos final, em que o eu lírico reconhece não qualquer tipo de preponderância egóica, mas o oposto disso - quer dizer: uma condição de dependência. Construído em estrutura anapéstica, o penúltimo verso, um trissílabo, já institui uma ruptura rítmica, encerrando as divagações e repetições presentes nos versos anteriores e abrindo espaço para o verso final: este, ao recuperar parcialmente a sonoridade do que o antecede (latejante / deseja), manifesta a urgência subjetiva de modo mais nítido.

Como compreender, afinal, essa demanda por amor? Por um lado, ela me parece indissociável das manifestações empáticas verbalizadas ao longo da composição: desejar amor é procurar, precisamente, por aquilo que possa representar uma forma de cura para um mundo povoado por um contingente de desfavorecidos, situação que decorre da injustiça social. Se recuperamos o motivo central das angústias que acometem o eu lírico presente no poema de Lia Vieira - ou seja: a fome -, podemos relembrar as observações do geógrafo negro Milton Santos, para quem a distribuição desigual é o que produz a sensação 
e a consciência da escassez (2001, p. 129); a tomada de consciência é o que pode constituir a cidadania, a partir de um entendimento amplo do processo social (2001, p. 139). Embora presente na subjetividade figurada na composição de Lia Vieira, esta vontade de transformação demanda a alteridade para efetivar-se; nesse sentido, o desejo de amor pode ser interpretado como a propensão à construção de relações empáticas que possam viabilizar esse movimento. Desejar o amor é, em outras palavras, desejar aqueles e aquelas que possam contribuir para a transformação do mundo em um lugar mais igualitário.

Por outro lado, não me parece ilegítimo perceber, nos versos finais, a expressão da carência afetiva em um sentido intrinsecamente erótico, ou seja: enquanto disposição para um encontro amoroso que ofereça uma resolução para a crise subjetiva. Para além de este não ser um campo temático estranho à obra literária de Lia Vieira, essa interpretação não implica uma contradição em relação ao anteriormente exposto, uma vez que se entenda a dimensão política dessa verbalização do desejo - não como interesse hedonista, mas como agência de um corpo negro e feminino que, apartando-se do lugar que lhe seria historicamente designado, deseja o amor como forma de potencializar-se 
para a ação transformadora sobre o real. Nessa medida, o amor constitui uma modulação da empatia, estendendo-se para um outro que metonimiza todos os corpos relegados à carência e a escassez: desejar o outro é, portanto, desejar fazer do mundo um lugar livre das opressões.

\section{SOBRE O DESEJO: “MEU ZUMBI”}

O segundo poema que analisarei foi originalmente publicado no décimo quinto volume dos Cadernos Negros. Comentar este poema me oferecerá uma oportunidade para dissertar mais extensamente sobre a abordagem do temário erótico na escrita de Lia Vieira. Transcrevo a composição:

Meu Zumbi

De corpo suado

De olhos meigos e doces

De boca ardente...

Nenhuma paisagem se iguala

à visão que tenho de você

Explosão de raça em forma de ser

o que mais quero:

Entrelaçar nossas peles retintas

Me animar de vida,

Buscar meu céu em sua terra

Saciar minha sede de mel em seu mistério.

Tatuar-te em meu corpo

para ter a certeza de tê-lo

preso-colado-filtrado em mim

na própria pele

rasgando a epiderme

que nem laser apaga 
que aos poucos me rasga

e se fixa e me marca

num uno indivisível.

(VIEIRA, 1992, p. 58)

De início, quero enfatizar que, também nesse caso, não cabe analisar a composição como inteiramente apartada de questionamentos políticos, precisamente pelas ponderações com as quais encerrei os comentários acerca de "Ânsia": em ambos os casos, estamos perante poemas que vocalizam o desejo de um corpo negro e feminino que desafia as estruturas historicamente impostas - racistas e patriarcais - para manifestar sua agência. Não obstante, neste segundo caso, a dimensão política do poema pode parecer menos explícita, como se toda a discursividade se concentrasse na expressão da libido. Minha interpretação buscará demonstrar que essa não é uma leitura pertinente, já por conta do verso que abre a composição. De resto, meus comentários se concentrarão em dois aspectos, sobretudo: na dimensão plástica do poema, evidente nas descrições dos corpos nele presentes; e no modo como a construção textual, em termos retóricos e rítmicos, concorre para a expressão desse desejo.

É preciso dedicar algum espaço ao verso que abre a composição, que opera como uma clave de leitura 
fundamental. Sua estrutura - como trissílabo anfímacro - concede ênfase ao pronome possessivo que abre a composição e ao segundo verso do nome próprio, de modo reforçar a relação entre o eu lírico e a alteridade desejada: há um eu que se lança para um outro e que dele se apropria, num gesto que pressupõe a entrega mútua. Todavia, é crucial observar o ato de nomeação que assim tem lugar. Ao atribuir ao corpo desejado o nome de Zumbi, Lia Vieira imediatamente evoca o maior símbolo de libertação constante da tradição negra brasileira: em que pesem as lacunas documentais, o mais conhecido líder da República de Palmares foi erigido, pela tradição negra brasileira, como ícone maior das lutas contra a opressão nas palavras de Clóvis Moura, se "atualmente considerado herói da resistência reivindicatória dos movimentos e grupos negros do Brasil", cabe considerar que "a reconstrução da sua biografia foi um esforço não apenas de pesquisa, mas também uma atividade de combate àqueles membros da historiografia tradicional que chegaram a negar-Ihe a existência" (2004, p. 425). A construção "Meu Zumbi", portanto, institui um sentido simultaneamente afetivo, enquanto relação de posse determinada por uma vinculação empática e existencial; e político, uma vez que o corpo amado é identificado ao ícone emancipatório. É 
indispensável, por conseguinte, atentar para o sentido revolucionário subjacente à construção do desejo na composição; e não menos imprescindível é compreender em que aspectos o erotismo é discursivamente enunciado em articulação com essa expressão subjetiva.

Nos versos seguintes (v. 2-4), tem lugar a descrição do corpo desejado; transcrevo-os recuperando o verso inicial, a fim de preservar a integridade do sentido:

\author{
Meu Zumbi \\ De corpo suado \\ De olhos meigos e doces \\ De boca ardente...
}

Em termos retóricos, parece-me importante destacar o ordenamento dos elementos evocados. Se o "corpo suado" tem uma acepção mais genérica, aludindo a uma disposição ativa, a menção a "olhos meigos e doces" concede à figuração um matiz que a aparta dos modos estereotipados de representação do corpo negro masculino, que usualmente fazem sobressair atributos como a força física ou a potência sexual; destarte, no poema de Lia Vieira ganham destaque aspectos associados à sensibilidade e à delicadeza, que em nada prejudicam o apelo erótico - explícito na menção à "boca ardente". Em termos rítmicos, o conjunto formado por esses três versos (v. 2-4) conjuga um redondilho menor, 
composto por um iambo e um anapesto; um hexassílabo, formado por dois troqueus e um iambo; e um tetrassílabo, composto por dois iambos. Há, portanto, um arranjo de inversões que, sustentando solidamente o andamento do poema, traduz as oscilações e variações intrínsecas aos processos de afirmação do ímpeto desejante.

No segmento seguinte (v. 5-12), o recurso a versos mais extensos viabiliza uma estabilização rímica, compatível com a modulação contemplativa do registro:

\author{
Nenhuma paisagem se iguala \\ à visão que tenho de você \\ Explosão de raça em forma de ser \\ o que mais quero: \\ Entrelaçar nossas peles retintas \\ Me animar de vida, \\ Buscar meu céu em sua terra \\ Saciar minha sede de mel em seu mistério.
}

A singularização do corpo descrito em cotejo com quaisquer paisagens acentua a posição do eu lírico, cuja voz assume um tom laudatório, deixando transparecer seu arroubo. Não por acaso, é nos versos seguintes que a racialização do corpo desejado ocorre de maneira mais explícita. Merece destaque o verso "[e]xplosão de raça em forma de ser", por sua estrutura atípica: decassilábica, mas não convencionalmente sáfica ou heroica; em vez disso, Lia Vieira compõe o verso com um anapesto e um iambo (pré- 
cesura) e um iambo e um anapesto (pós-cesura). Trata-se de uma estrutura raríssima, postulada por Manuel Cavalcanti Proença (1955, p. 92-94) a partir dos critérios propostos por Said Ali (considerando, portanto, a impossibilidade de justaposição de duas tônicas e admitindo, no máximo, três átonas em sequência); não obstante, essa possibilidade rítmica não é considerada pelos mais conhecidos preceptistas da poética em língua portuguesa - embora seja possível aproximá-la do decassílabo de arte maior (SPINA, 2003, p. 52-53). A atipicidade desse verso demanda, portanto, alguns comentários.

Em primeiro lugar, é notável que este verso possa ser lido como uma síntese do poema, na medida em que legitima a relação que se estabelece entre a subjetividade lírica e seu amado: se para "Zumbi" - nomeação que, como enfatizei, explicita a qualificação do corpo desejado como símbolo de liberdade - se direciona afetivamente a voz poética, isso está profundamente vinculado à sua condição racializada; o que diz respeito, por óbvio, à sua constituição ontológica (a "forma de ser"). Mas cabe observar, num segundo momento, que a simetria subjacente à composição rítmica do verso implica um ordenamento do desejo - como se este, finalmente, encontrasse o seu lugar, estabilizando-se no instante em 
que compreende sua própria natureza. A esse propósito, a localização dos anapestos na estrutura métrica sugere uma movimentação constante, mas direcionada; como um ímpeto que avança para seu objeto, refreia-se por um par de momentos e volta a avançar - reunindo, eventualmente, as condições para perdurar, num moto contínuo. Reúnem-se, portanto, plenamente os elementos para o enlace amoroso, descrito nos versos subsequentes, abertos por um curto verso tetrassilábico ("o que mais quero", v. 8).

Na descrição da ansiada fusão dos corpos, a voz lírica explicita sua negritude: o entrelaçamento das "peles retintas" implica um enfrentamento frontal das estruturas racistas - considerando-se, mais especificamente no caso brasileiro, a histórica implantação de políticas nacionais que tiveram como ostensivo propósito o embranquecimento da população, com o consequente apagamento de quaisquer traços negros da sociedade brasileira. A celebração do amor entre dois corpos negros constitui, destarte, um ato subversivo, em que é nítido o investimento político já explicitado, na abertura do poema, pela nomeação do amado. Em termos formais, vale destacar a estruturação do verso "[e]ntrelaçar nossas peles retintas" como um decassílabo composto à maneira de um peão quarto e dois anapestos: 
assim, sustenta-se o ritmo imposto pelo decassílabo anterior, já extensamente comentado, mas instituindo um andamento diverso. Ocupando o espaço medial, o tetrassílabo realiza perfeitamente a transição de uma composição rítmica para a outra. No verso propriamente dito (v. 9), a acentuação deslocada para a quarta sílaba confere uma cadência mais convencional para o poema (como um modo de "resolver" o arranjo presente no hemistíquio inicial do decassílabo anterior, que pode ser lido como junção de um anapesto e um iambo); por outro lado, os anapestos presentes neste nono verso retêm sutilmente o avanço sugerido pelo segmento inicial - como se o ímpeto desejante procurasse dosar-se, de maneira a desfrutar mais intensamente o momento de gozo. Os efeitos do prazer sobre a subjetividade lírica são enunciados nos versos que encerram a primeira estância. $O$ encontro amoroso enseja não apenas um revigoramento (v. 10: "Me animar de vida") mas também um êxtase em direção ao infinito, em termos espaciais (v. 11: "Buscar meu céu em sua terra") ou ontológicos (v. 12: "Saciar minha sede de mel em seu mistério"), ainda que inevitavelmente projetados no corpo alheio.

$\mathrm{Na}$ segunda estrofe do poema, prossegue a enunciação do desejo: 


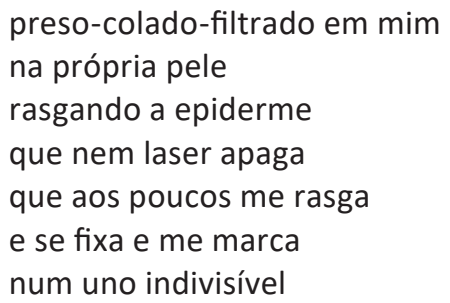

Já de início, a subjetividade lírica manifesta o anelo de prolongar indefinidamente a experiência erótica, inscrevendo-a em si. Embora, em um momento inicial, essa inscrição ocorra numa dimensão mais superficial - por intermédio da indelével tatuagem ("que nem laser apaga": v. 18), gravando na própria carne o outro, -, o que constitui uma maneira de cristalizar definitivamente a relação afetiva (mantendo o corpo amado "preso-colado-filtrado", enumeração de forte sentido retórico, à "própria pele": v. 15-16), esse procedimento logo avança para camadas mais profundas, "rasgando a epiderme" (v. 17). Não obstante, a visão dicotômica que cinde o corpo em uma dimensão exterior (isto é: o "fora”, identificado à superfície epidérmica) e outra interior (o "dentro", compreendido como a instância ontologicamente mais relevante) é questionada pelo discurso lírico, quando este afirma que rasgar a epiderme implica rasgar a própria subjetividade (v. 19). O que resulta desse processo é, afinal, a fusão entre os dois corpos, entendida como uma síntese que abarca integralmente as 
duas subjetividades: ao cindir o eu, o outro abre o caminho que lhe permite fixar-se de modo perene, sedimentando a fusão definitiva: origina-se, do enlace, a indivisível unidade dos corpos (v. 21).

Vale notar a regularidade métrica perceptível nessa estância final, com o recurso a hexassílabos que estruturam ritmicamente o segmento (vv. 13, 18, 20 e 21), entremeados por versos mais longos (v. 14 e 15, eneassilábicos) ou mais curtos (v. 16, tetrassilábico; v. 17 e 19, pentassilábicos), cuja regularidade não impõe oscilações severas ao andamento da composição. Tudo isso concorre para sugerir um progressivo abrandamento do desejo nessa estrofe derradeira - não em decorrência de sua extinção, decerto; mas como um processo de estabilização no corpo alheio, efeito de uma reciprocidade plena que enseja a síntese definitiva.

\title{
À GUISA DE CONCLUSÃO
}

Lia Vieira abre sua "Auto-biografia" poética com estes versos:

\author{
Nasci grande \\ nasci escrevendo \\ Já Negra bela \\ Já mulher. \\ (VIEIRA, 2019, p. 228)
}

O que encontramos, neste trecho inicial do poema, é um resgate do processo de autorreconhecimento de uma 
pessoa, que, desde um primeiro momento, percebe-se marcada por raça e por gênero; portanto, como negra e mulher. Resultantes de uma designação efetivada a partir de elementos corporais particulares, essas marcações determinam o deslocamento para uma posição social e política específica: precisamente aquela que, no Brasil, é alvo de dupla opressão, em decorrência de basilares estruturas racistas e patriarcais.

O reconhecimento dessa condição subjaz ao projeto estético de Lia Vieira, enquanto expressão de uma subjetividade que encara o desafio de erguer-se contra as dinâmicas de poder prevalecentes. A associação entre o ato de escrita e o nascimento tem o efeito de vincular a criação literária à existência, em um sentido radical - e sugerir, por outro lado, que o próprio ato de viver constitui uma modalidade de escritura. Disso deriva a centralidade dos afetos na de Lia Vieira, não apartados da consciência política - algo transparente nas leituras aqui propostas para duas peças de sua lavra poética.

Termino citando os versos que encerram a "Autobiografia":

Ousei, questionei, debati

Encontrei na escrita

A forma, a força, feliz 
E nela sobrevivi.

(VIEIRA, 2019, p. 228)

Fazendo da escrita um compromisso existencial, Lia Vieira construiu uma trajetória que Ihe permitiu alçar-se à posição de uma das mais potentes vozes da literatura negro-brasileira - fazendo, simultaneamente, da felicidade um caminho para a libertação.

\section{REFERÊNCIAS}

CARNEIRO, Sueli. Racismo, sexismo e desigualdade no Brasil. São Paulo: Selo Negro, 2011.

DUARTE, Eduardo de Assis. Literatura e afrodescendência no Brasil: antologia crítica. vol. 3: contemporaneidade. Belo Horizonte: Editora UFMG, 2014.

JESUS, Carolina Maria de. Quarto de despejo. São Paulo: Francisco Alves, 1960.

JESUS, Carolina Maria de. Pedaços da fome. São Paulo: Áquila, 1963a.

JESUS, Carolina Maria de. Provérbios. São Paulo: [s.n.], 1963b.

MOURA, Clóvis. Dicionário da escravidão negra no Brasil. São Paulo:

Editora da Universidade de São Paulo, 2004.

PROENÇA, Manuel Cavalcanti. Ritmo e poesia. Rio de Janeiro: Simões Editores e Livraria, 1955.

SANTOS, Milton. Por uma outra globalização: do pensamento único à consciência universal. 6. ed. Rio de Janeiro: Record, 2001.

SPINA, Segismundo. Manual de versificação românica medieval. Cotia: Ateliê Editorial, 2003.

TRINDADE, Solano. Cantares ao meu povo. São Paulo: Fulgor, 1961.

VIEIRA, Lia. Meu Zumbi. Cadernos Negros, n. 15. São Paulo:

Quilombhoje, 1992. 
VIEIRA, Lia. Ânsia. Cadernos Negros, n. 19. São Paulo: Quilombhoje, 1996.

VIEIRA, Lia. Ânsia. In: SEMOG, Éle (Org.). Amor e outras revoluções:

Grupo Negrícia - antologia poética. Rio de Janeiro: Malê, 2019.

VIEIRA, Lia. Auto-biografia. In: SEMOG, Éle (Org.). Amor e outras

revoluções: Grupo Negrícia - antologia poética. Rio de Janeiro: Malê, 2019.

Henrique Marques Samyn

Doutor (Universidade do Estado do Rio de Janeiro - UERJ).

Professor graduação e pós-graduação (UERJ).

Coordena o projeto de extensão "LetrasPretas" (UERJ); membro da equipe do Gabinete em Estudos de Gênero da Universidade de Lisboa. http://lattes.cnpq.br/7887811794725020

https://orcid.org/0000-0002-2624-3487

marquessamyn@gmail.com 